\title{
Effectiveness, Safety and Tolerability of Vildagliptin with or without Metformin in Bangladeshi Patients with Type 2 Diabetes Mellitus: Results from Real-Life Observational Study
}

\author{
Latif ZA ${ }^{\mathrm{a}}$, Pathan $\mathrm{MF}^{\mathrm{b}}$, Uddin $\mathrm{MF}^{\mathrm{c}}$, Hasanat MA ${ }^{\mathrm{d}}$, Ashrafuzzaman $\mathrm{SM}^{\mathrm{e}}$, Ali TM${ }^{\mathrm{f}}$, Rahman MM ${ }^{\mathrm{g}}$
}

\begin{abstract}
Background: Type 2 diabetes mellitus (T2DM) is a progressive disease which needs prolonged management with anti-diabetic drugs. The purpose of the present study was to assess effectiveness, safety and tolerability of treatment by vildagliptin alone or with the combination of vildagliptin and metformin in T2DM patients in a real-world setting.

Methods: This non-interventional, prospective, multi-center study was conducted in several hospitals in Bangladesh from $15^{\text {th }}$ September 2010 to $12^{\text {th }}$ June 2012. Both male and female patients, aged $\geq 18$ years with an established diagnosis of T2DM, who had been prescribed vildagliptin or vildagliptin added to metformin free-dose or single-pill combination according to local prescribing information and who consented to data collection, were eligible for inclusion in the study. During the observational period of $24 \pm 6$ weeks, data from three routine clinic visits were recorded; i.e. the baseline visit (Day 1), visit 2 (week $12 \pm 4$ weeks) and a final visit (visit 3) at the end of the study (week $24 \pm 6$ weeks).

Result: A total number of 510 patients were enrolled in this study of which 468 patients were analyzed for the study and the remaining 42 patients were lost to follow up. Patients in vildagliptin group were treated with vildagliptin as monotherapy which was received by 101 patients; however, patients in vildagliptin/metformin group received the combination of vildagliptin and metformin which was in 367 cases. In vildagliptin group, the mean HbAlc was

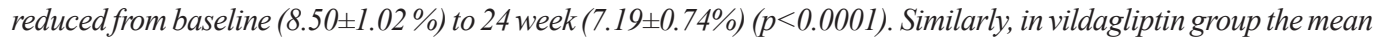
HbAlc at week $12(7.76 \pm 0.96 \%)$ was lower vs. baseline $(8.50 \pm 1.02 \%)(p<0.0001)$. In vildagliptin and metformin combination group, the mean HbAlc at week 24 (7.02 $\pm 0.66 \%)$ was lower vs. baseline $(8.55 \pm 0.75 \%)(p<0.0001)$. There were no deaths and no serious adverse effects. None of the patients reported any hypoglycemic event.

Conclusion: In conclusion vildagliptin treating T2DM patients with or without metformin is associated with a significant and clinically relevant improvement in glycaemic control. Furthermore, vildagliptin treatment is generally well tolerated.
\end{abstract}

Keywords: efficacy; metformin; safety; type 2 diabetes mellitus; vildagliptin.

Birdem Med J 2016; 6(1): 12-17

\section{Author Informations}

a. Prof. Zafar Ahmed Latif, Professor of Endocrinology and Director, BIRDEM Academy, BIRDEM General Hospital, Bangladesh.

b. Prof. Md. Faruque Pathan, Professor and Head, Department of Endocrinology, BIRDEM General Hospital, Bangladesh.

c. Prof. Md. Farid Uddin, Professor, Department of Endocrinology, BSMMU, Bangladesh.

d. Prof. M A Hasanat, Professor and Chairman, Department of Endocrinology, BSMMU, Bangladesh.

e. Dr. S M Ashrafuzzaman, Associate Professor, Department of Endocrinology, BIRDEM General Hospital, Bangladesh.

f. Dr. Tanvir Mobarak Ali, Chief Scientific Officer, Novartis (Bangladesh) Limited.

g. Dr. Md. Mahfuzur Rahman, Medical Advisor, Novartis (Bangladesh) Limited.

Address of correspondence: Prof. Zafar Ahmed Latif, Professor of Endocrinology and Director, BIRDEM Academy, BIRDEM General Hospital, 122, Kazi Nazrul Islam Avenue, Shahbagh, Dhaka1000, Bangladesh. Email: zafaralatif2011@yahoo.com

Received: June 12, 2015

Accepted: November 30, 2015

\section{Introduction}

Type 2 diabetes mellitus (T2DM) patients number is increasing due to population growth, aging, urbanization and increasing prevalence of obesity and physical inactivity. ${ }^{1}$ The total number of people with diabetes is projected to rise from more than 371 million in 2012 to half a billion ( 552 million) in 2030 globally and posing a major burden on world health. ${ }^{2}$ In Bangladesh, the projected number of diabetes cases in 2030 is expected to be approximately 16,837 lakhs. ${ }^{3}$

The management of T2DM primarily targets the treatment of hyperglycemia through oral anti-diabetic drugs (OADs) with or without insulin therapy. ${ }^{4}$ Therefore the uses of OADs are the main choice for the treating T2 DM patients. OADs like secretagogues trigger insulin release or production from the pancreatic $\beta$ cells, sensitizers either reduce the hepatic glucose 
output (metformin) or enhance insulin sensitivity, retard glucose uptake from the gastrointestinal tract. ${ }^{5}$ Though the existing OAD monotherapy provide short-term glycemic control, they are often associated with adverse effects like weight gain, hypoglycemia, gastrointestinal disturbances and edema, thereby limiting their tolerability. ${ }^{6}$ Vildagliptin is an agent of a new class of OADs which improves glycemic control by elevating levels of glucagon like peptide- 1 and glucose-dependent insulinotropic polypeptide through inhibition of dipeptidyl peptidase 4 (DPP-4). ${ }^{7}$

Vildagliptin and the combination of vildagliptin and metformin are authorized for use in the treatment of T2DM in most countries in region of Asia-Pacific, Middle-East and African countries and many other countries worldwide. ${ }^{5}$ Although the efficacy and safety profile of vildagliptin and combination of vildagliptin and metformin in randomized controlled trials (RCTs) are well established ${ }^{8-10}$, demonstration of its true clinical effectiveness in routine clinical practice is limited. In this context the lack of data regarding this issue, has directed for doing this study. Furthermore T2DM is going to be one of the main crises in the health sectors. Thus use of OADs has given the uplifting the burden of the costing of insulin. Therefore, the purpose of this observational study was to evaluate the effectiveness, safety and tolerability of treatment with vildagliptin or combination of vildagliptin with metformin in T2DM patients in a real-world setting.

\section{Methods}

The study was a multicentre, post-authorization, noninterventional, prospective study that pooled data for analysis from GUARD (vildaGliptin clinical Use in the reAl woRID) study, conducted in Asia, the Middle-East, Central America and Africa, according to one umbrella protocol. This study was conducted in several hospitals in Bangladesh from $15^{\text {th }}$ September 2010 to $12^{\text {th }}$ June 2012 for a period of one year and nine months. The study complied with all required guidelines, local regulations and the Declaration of Helsinki. Both male and female outpatients with T2DM in the age group of $\geq 18$ years who had been prescribed vildagliptin (Galvus) or vildagliptin (Galvus) added to metformin (open label) in free-dose or single pill combination according to local prescribing information and who had given consent to participate in this study, were included as study population. Data originating from assessments and evaluations performed according to the physician's routine practice and standard care was recorded. During the observational period of $24 \pm 6$ weeks, data from three routine patient visits were recorded: the baseline visit (Day 1), Visit 2 (12 \pm 4 weeks) and a final visit (Visit 3 ) at study end ( $24 \pm 6$ weeks). The primary effectiveness endpoint was change in mean glycated haemoglobin (HbAlc) concentration from baseline to final visit at 24 \pm 6 weeks. Key secondary endpoints included the proportion of patients reaching a target $\mathrm{HbA} 1 \mathrm{c}$ of $\leq 6.5$ and $\leq 7.0 \%$ at week 24 , changes in body weight and body mass index (BMI) from baseline to week 24, and the number of patients experiencing a hypoglycaemic event. Safety and tolerability were also assessed by recording and evaluating adverse effects (AEs) and serious AEs (SAEs). Assessment of whether AEs/SAEs were considered to be related or unrelated to the medication of interest was carried out by the treating physician. Supportive analyses of covariance were performed to assess the change from baseline $\mathrm{HbA} 1 \mathrm{c}$ in relation to different patient subgroups, categorized according to baseline $\mathrm{HbA1c}$, patient age and obesity status. No diagnostic or monitoring procedures additional to standard care and routine practice were applied to the patients, and epidemiological methods were used for the analysis of collected data. The statistical tables and listings were generated using SAS $^{\circledR}$ version 9.2. Summary statistics for quantitative variables included the number of observations, mean, standard deviation, median, minimum, and maximum, and for qualitative variables included number and percentage of patients in frequency tables. The primary effectiveness variable was the status effect of vildagliptin as monotherapy or in addition to metformin on change from baseline in $\mathrm{HbA} 1 \mathrm{c}$ after 24 weeks treatment. The two-sided $95 \%$ confidence interval for the estimated difference was presented. A p-value less than 0.05 indicated that the mean change from baseline in $\mathrm{HbA} 1 \mathrm{c}$ in the treatment group was significantly different from zero.

\section{Results}

A total number of 510 patients were enrolled in this study, of which 42 patients were excluded from the analyses due to lost to follow up. Therefore total 468 patients were analyzed in this study of which 101 patients in the vildagliptin group and 367 patients in combination of vildagliptin and metformin group. Of 
these, $438(93.6 \%)$ patients completed the study while $30(6.4 \%)$ patients discontinued. The primary reasons for discontinuation were lost to follow-up [28 (6.0\%)], AEs and withdrawal of consent $[1(0.2 \%)$ each]. Fourteen patients in the monotherapy group were also treated with other oral anti-diabetic medications. The mean age of patients was $47.1 \pm 8.40$ years and majority [455 (97.2\%)] were less than 65 years of age. There were $274(58.5 \%)$ male and 194 (41.5\%) female patients. The mean BMI of the patients was $26.3 \pm 3.84 \mathrm{~kg} / \mathrm{m}^{2}$ and majority [314 $(67.1 \%)]$ had BMI $<30 \mathrm{~kg} / \mathrm{m}^{2}$. The mean Baseline HbA1c was $8.50 \pm 0.81 \%$ and for majority [273 (58.3\%)] of the patients $\mathrm{HbAlc}$ was in the range of $>8 \%$ to $9 \%$, for $120(25.6 \%)$ in the range of $\leq 8 \%, 36(7.7 \%)$ in the range of $>9 \%$ to $10 \%$ and $21(4.5 \%)$ had baseline $\mathrm{HbAlc}>10 \%$ (Table-I).

Table-I. Demographic and Baseline Characteristics

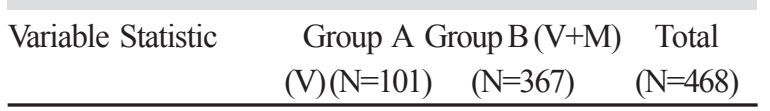

Age group

Mean (SD)

$45.6( \pm 8.72) 47.5( \pm 8.27) 47.1( \pm 8.40)$

Sex, n (\%)

$\begin{array}{llll}\text { Male } & 60(59.4) & 214(58.3) & 274(58.5)\end{array}$

$\begin{array}{llll}\text { Female } & 41(40.6) & 153(41.7) & 194(41.5)\end{array}$

HbA1c group, n (\%)

Baseline Mean (SD) $8.50( \pm 1.02) \quad 8.60( \pm 0.75) 8.50( \pm 0.81)$

$\mathrm{HbA} 1 \mathrm{c} \leq 8 \% \quad 32(31.7) \quad 88(24.0) \quad 120(25.6)$

$\mathrm{HbA} 1 \mathrm{c}>8 \%-9 \% \quad 52(51.5) \quad 221(60.2) \quad 273(58.3)$

$\mathrm{HbAlc}>9 \%-10 \% \quad 7(6.9) \quad 29(7.9) \quad 36(7.7)$

$\mathrm{HbA} 1 \mathrm{c}>10 \% \quad 7(6.9) \quad 14(3.8) \quad 21(4.5)$

Weight, kilograms

Mean (SD)

$\begin{array}{ccc}68.1 & 68.8 & 68.6 \\ ( \pm 9.19) & ( \pm 10.87) & ( \pm 10.56)\end{array}$

BMI group, $\mathrm{n}(\%)$

$\mathrm{BMI}<30 \mathrm{~kg} / \mathrm{m}^{2} \quad 67(66.3) \quad 247(67.3) \quad 314(67.1)$

$\mathrm{BMI} \geq 30 \mathrm{~kg} / \mathrm{m}^{2} \quad 10(9.9) \quad 58(15.8) \quad 68(14.5)$

Mean (SD) kg/m² $25.5( \pm 3.48) \quad 26.5( \pm 3.90) 26.3( \pm 3.84)$

Duration of T2DM, yrs

\begin{tabular}{|c|c|c|}
\hline Mean (SD) & $1.2( \pm 2.53)$ & $3.9( \pm 4.50)$ \\
\hline
\end{tabular}

${ }^{1}$ Prior to study start; $\mathrm{BMI}=$ Body mass index; $\mathrm{SD}=$ Standard deviation; T2, DM= Type 2 diabetes mellitus; $\mathrm{V}=$ Vildagliptin; $\mathrm{V}+\mathrm{M}=$ Vildagliptin + Metformin

In vildagliptin + metformin group, the mean $\mathrm{HbA} 1 \mathrm{c}$ at week 24 ( $7.02 \pm 0.66 \%)$ was lower than baseline $(8.55 \pm$ $0.75 \%$ ), and the change was statistically significant $(p<0.0001)$. In vildagliptin group, there was a significant $(p<0.0001)$ reduction from baseline to week 24 in HbA1c values (Table-II).

Table II. Change from Baseline in $\mathrm{HbA1c}$ Results in 24th Week [Mean $( \pm \mathrm{SD})]$

\begin{tabular}{lccc}
$\begin{array}{l}\text { Primary Efficacy } \\
\text { Variable: HbA1c }\end{array}$ & $\begin{array}{c}\text { Group A } \\
(\mathrm{V})\end{array}$ & $\begin{array}{c}\text { Group B } \\
(\mathrm{V}+\mathrm{M})\end{array}$ & Total \\
Baseline & $8.50 \pm 1.02$ & $8.55 \pm 0.75$ & $8.54 \pm 0.81$ \\
Week 24(LOCF) & $7.19 \pm 0.74$ & $7.02 \pm 0.66$ & $7.06 \pm 0.68$ \\
\hline P value & $<0.0001$ & $<0.0001$ & $<0.0001$
\end{tabular}

Baseline $=$ Week 0; if week 24 assessment was missing, the last post baseline observation was carried forward; LOCF $=$ Last observation carried forward; $\mathrm{SD}=$ Standard deviation; $\mathrm{V}=$ Vildagliptin; $\mathrm{V}+\mathrm{M}=$ Vildagliptin+Metformin In vildagliptin group, there were 17 (16.8\%) patients who reached the HbAlc target value of $\leq 6.5 \%$ and 45 (44.6\%) patients who reached the HbA1c target value of $\leq 7.0 \%$. In vildagliptin + metformin group, there were $77(21.0 \%)$ patients who reached the HbAlc target value of $\leq 6.5 \%$ and $198(54.0 \%)$ patients who reached the HbAlc target value of $\leq 7.0 \%$ (Table III).

Table III. Number (\%) of Patients Reaching HbA1c Targets after 24 Weeks of Treatment

HbAlc GroupA(V) Group B(V+M) Total

\begin{tabular}{lllr} 
& $(\mathrm{N}=101)$ & $(\mathrm{N}=367)$ & $(\mathrm{N}=468)$ \\
\hline$<\mathbf{6 . 5 \%}$, n $(\%)$ & $17(16.8)$ & $77(21.0)$ & $94(20.1)$ \\
$<\mathbf{7 . 0 \%}$, n $(\%)$ & $45(44.6)$ & $198(54.0)$ & $243(51.9)$ \\
\hline
\end{tabular}

There were no patients with AEs. There were no deaths and no SAEs. There was $1(0.3 \%)$ patient who discontinued due to an AE; however the AE was categorized as non-serious. None of the patients reported any hypoglycemic events (Table IV).

At week 24, in vildagliptin group, mean (SE) body weight change $(\mathrm{kg})$ and BMI $\left(\mathrm{kg} / \mathrm{m}^{2}\right)$ reduction were $-1.98(0.36)$ and $-0.71(0.13)$ respectively, both of which were statistically significant (P-value $<0.0001)$. For vildagliptin+metformin group also the mean (SE) body weight change $(\mathrm{kg})$ and BMI $\left(\mathrm{kg} / \mathrm{m}^{2}\right)$ reduction [-1.78 $(0.17)$ and $-0.64(0.08)$ respectively] were statistically significant $(\mathrm{P}$-value $<0.0001)$. 
Table-IV. Patients with Death, Serious Adverse Events, or Adverse Events Leading to Medication of Interest Discontinuation

\begin{tabular}{lccc} 
Outcomes & $\begin{array}{c}\text { Group A } \\
(\mathrm{N}=101)\end{array}$ & $\begin{array}{c}\text { Group B } \\
(\mathrm{N}=367)\end{array}$ & $\begin{array}{c}\text { Total } \\
(\mathrm{N}=468)\end{array}$ \\
\hline Deaths, n (\%) & $0(0)$ & $0(0)$ & $0(0)$ \\
SAEs, n (\%) & $0(0)$ & $0(0)$ & $0(0)$ \\
Discontinued & $0(0)$ & $1(0.3)$ & $1(0.2)$ \\
Due to SAE, n (\%) & $0(0)$ & $0(0)$ & $0(0)$ \\
Due to AE, n (\%) & $0(0)$ & $1(0.3)$ & $1(0.2)$ \\
Hypoglycaemia & $0(0)$ & $0(0)$ & $0(0)$ \\
\hline
\end{tabular}

$* \mathrm{SAE}=$ Serious Adverse Event

\section{Discussion}

The combination of vildagliptin and metformin as prescribed in free-dose or combination in different studies have shown significant reduction of blood sugar as well as HbA1c. ${ }^{11-12}$ Several RCTs carried out to see the safety, efficacy and tolerability of vildagliptin..$^{8-10}$ However an advantage of observational studies is the access to large, diverse groups of patients who better represent the population to which a drug is prescribed, and safety and effectiveness data collected from these studies are valuable in clinical practice. Vildagliptin and the combination of vildagliptin and metformin are authorized for use in the treatment of T2DM in many countries worldwide. ${ }^{5}$

In this study the results showed that there was a significant change from baseline in $\mathrm{HbA1}$ c after 24 weeks treatment with vildagliptin as monotherapy and vildagliptin and metformin combination therapy ( $\mathrm{p}<$ 0.0001 ). The mean change from baseline in $\mathrm{HbA} 1 \mathrm{c}$ after 24 weeks treatment with vildagliptin alone and vildagliptin with metformin was similar to that reported in various RCTs for vildagliptin ${ }^{8-10}$ and vildagliptin + metformin. ${ }^{13-15}$ These findings support the results from RCTs, where the magnitude of $\mathrm{HbA} 1 \mathrm{c}$ reductions with vildagliptin ${ }^{16}$ and vildagliptin+metformin was greater in patients with higher baseline $\mathrm{HbA} 1 \mathrm{c} .{ }^{17}$ Approximately, $16.8 \%$ patients reached the $\mathrm{HbA} 1 \mathrm{c}$ target value of $\leq 6.5 \%$ and $44.6 \%$ patients reached the $\mathrm{HbA} 1 \mathrm{c}$ target value of $\leq 7 \%$ with vildagliptin as monotherapy suggesting a good glycemic control in 24 weeks. Similarly, $21.0 \%$ patients reached the $\mathrm{HbA} 1 \mathrm{c}$ target value of $\leq 6.5 \%$ and
$54.0 \%$ patients reached the $\mathrm{HbA} 1 \mathrm{c}$ target value of $\leq 7 \%$ with combination of vildagliptin and metformin, again suggesting a good glycemic control in 24 weeks. There was a significant change from baseline body weight and BMI after 24 weeks of vildagliptin as well as combination of vildagliptin and metformin. Reduction in weight was also observed in few trials with vildagliptin as monotherapy. ${ }^{18}$

There were no discontinuations due to unsatisfactory effectiveness or need for an additional OAD or insulin, which is in-line with data from RCTs. ${ }^{15}$ Investigator assessment scores for vildagliptin and combination of vildagliptin and metformin were good to very good for effectiveness, tolerability, and compliance, and the decision to continue the treatment with vildagliptin or vildagliptin and metformin was made for most $(96.2 \%)$ of the patients in the study in the study population. There were no deaths and no SAEs in either of the treatment groups, and one patient discontinued due to $\mathrm{AE}$ in vildagliptin + metformin group. None of the patients reported any hypoglycemic events. These results are similar to that obtained in RCTs. ${ }^{15-17}$ Vildagliptin and combination of vildagliptin and metformin were both well tolerated, and there were no patients who reported SAE. It is interesting to get the result which is statistically significant. In Bangladesh, so far this type of study has not been performed to evaluate effectiveness of vildagliptin alone or with the combination of metformin.

In vildagliptin and metformin combination group, the within treatment comparison for change from baseline to week 24 in HbA1c for Full Analysis Set (FAS) showed a significant $(\mathrm{p}<0.0001)$ reduction from baseline to week 24, and baseline $\mathrm{HbA1c}$, BMI group, and gender had a significant impact on the change in $\mathrm{HbA} 1 \mathrm{c}$ from baseline to week $24(\mathrm{P}=0.000, \mathrm{P}=0.043$, and $\mathrm{p}=0.045$, respectively $)$ while age group did not affect the results significantly. In vildagliptin and metformin combination group, there were $77(21.0 \%)$ patients who reached the HbAlc target value of $\leq 6.5 \%$ and $198(54.0 \%)$ patients who reached the $\mathrm{HbA} 1 \mathrm{c}$ target value of $\leq 7 \%$. In vildagliptin group, the change from baseline in body weight was statistically significant $(\mathrm{P}<0.0001)$, and significant covariates were BMI group $(\mathrm{P}=0.014)$. The change from baseline in BMI after 24 weeks of treatment was also statistically significant $(\mathrm{P}<0.0001)$, and $\mathrm{BMI}$ group $(\mathrm{P}=0.006)$, were significant covariates. In vildagliptin and metformin 
combination group, the change from baseline in body weight was statistically significant $(P<0.0001)$, and significant covariates was $\mathrm{BMI}$ group $(\mathrm{P}=0.000)$. The change from baseline in BMI after 24 weeks of treatment was also statistically significant $(\mathrm{P}<0.0001)$, and BMI group $(P=0.000)$ was significant covariate. There were no patients who discontinued due to unsatisfactory effectiveness or who needed additional OAD or insulin in FAS. The results confirm the effectiveness, safety, and tolerability data for vildagliptin and combination of vildagliptin and metformin demonstrated in RCTs. This is relevant as observational studies assess the effectiveness of a drug previously documented to be efficacious in controlled environment in a real-world setting. Therefore, it provides information on how a drug works in daily practice, under ordinary and variable conditions, prescribed by physicians with varying degrees of knowledge and expertise, to treat a variety of eligible patients. The result demonstrated that vildagliptin as monotherapy, and in combination with metformin was effective in large, diverse group of patients representing the population to which the drug is prescribed. The safety and effectiveness data collected from this study is hence valuable for clinical practice. There were several patients who had to be excluded from analysis as data was incomplete or missing for these patients. Despite these limitations this data provides a real-world experience with respect to effectiveness, safety and tolerability of vildagliptin as monotherapy, and also in combination with metformin.

\section{Conclusion}

Vildagliptin treatment with or without metformin provided consistent, clinically relevant improvements in glycaemic control, regardless of baseline $\mathrm{HbAlc}$, obesity status and age, and was well tolerated in routine clinical practice.

\section{Acknowledgment}

The authors acknowledge all investigators at the participating centers and all patients for their commitment to the study that was supported by Novartis Pharma AG, Basel, Switzerland and Novartis (Bangladesh) Limited. Xplore Business Limited, Dhaka provided the medical writing for the manuscript. All authors participated in the development and reviewing of the manuscript and took full responsibility for the contents of the article. The study was funded by the
Novartis Pharma Bangladesh.

Funding agency: Novartis (Bangladesh) Limited, 13, Bir Uttam C.R. Dutta Road, Biponan C/A, Dhaka-1000, Bangladesh.

\section{References}

1. American Diabetes Association. Standards of medical care in diabetes- 2010. Diabetes Care 2010; 33: S11-S61.

2. Shaw JE, Sicree RA, Zimmet PZ. Global estimates of the prevalence of diabetes for 2010 and 2030. Diabetes research and clinical practice 2010;87:4-14.

3. Wild S, Roglic G, Green A, Sicree R, King H. Global prevalence of diabetes estimates for the year 2000 and projections for 2030. Diabetes care 2004;27:1047-53.

4. Qaseem A, Humphrey LL, Sweet DE, Starkey M, Shekelle P. Oral pharmacologic treatment of type 2 diabetes mellitus: a clinical practice guideline from the American College of Physicians. Ann Intern Med. 2012;156(3): 218-31.

5. Kaplan W. Background Paper 6.4 Diabetes. Priority Medicines for Europe and the World. A Public Health Approach to Innovation. 2013.

6. Bron M, Marynchenko M, Yang H, Yu AP, Wu EQ. Hypoglycemia, treatment discontinuation, and costs in patients with type 2 diabetes mellitus on oral antidiabetic drugs. Postgrad Med. 2012;124:124-32.

7. Ristic S, Bates PC. Vildagliptin: a novel DPP-4 inhibitor with pancreatic islet enhancement activity for treatment of patients with type 2 diabetes. Drugs Today (Barc) 2006;42(8):519-31.

8. Dejager S, Schweizer A, Foley JE. Evidence to support the use of vildagliptin monotherapy in the treatment of type 2 diabetes mellitus. Vascular health and Risk Management $2012 ; 8: 339$

9. Schweizer A, Dejager S, Bosi E. Comparison of vildagliptin and metformin monotherapy in elderly patients with type 2 diabetes: a $24 \cdot$ week, double-blind, randomized trial. Diabetes, Obesity and Metabolism 2009;11:804-12.

10. Pan C, Yang W, Barona JP, Wang Y, Niggli M, Mohideen $P$, et al. Comparison of vildagliptin and acarbose monotherapy in patients with Type 2 diabetes: a 24 week, double-blind, randomized trial. Diabetic Medicine 2008;25:435-41.

11. Schweizer A, Couturier A, Foley JE, Dejager S. Comparison between vildagliptin and metformin to sustain reductions in HbAlc over 1 year in drug naive patients with Type 2 diabetes. Diabetic Medicine 2007;24:955-61.

12. Barnett AH. Translating science into clinical practice: focus on vildagliptin in combination with metformin. Diabetes, Obesity and Metabolism 2009;11:18-26. 
13. Chatterjee S, Chatterjee S. Vildagliptin With Metformin Once-Daily Regimen-Insights From a Single-Center Analysis. Am J Ther. 2013;20(3):288-91

14. Bluher M, Kurz I, Dannenmaier S, Dworak M. Efficacy and safety of vildagliptin in clinical practice-results of the PROVIL-study. World journal of diabetes 2012; 3(9): $161-69$

15. Pan C, Xing X, Han P, Zheng S, Ma J, Liu J, et al. Efficacy and tolerability of vildagliptin as addâ•• on therapy to metformin in Chinese patients with type 2 diabetes mellitus. Diabetes, Obesity and Metabolism 2012;14: 737-44

16. Goodman M, Thurston H, Penman J. Efficacy and tolerability of vildagliptin in patients with type 2 diabetes inadequately controlled with metformin monotherapy. Hormone and Metabolic Research 2009;41:368-73.

17. Bosi E, Dotta F, Jia Y, Goodman M. Vildagliptin plus metformin combination therapy provides superior glycaemic control to individual monotherapy in treatment naive patients with type 2 diabetes mellitus. Diabetes, Obesity and Metabolism 2009; 11: 506-15.

18. Goke B, Hershon K, Kerr D, Calle PA, Schweizer A, Foley J, et al. Efficacy and safety of vildagliptin monotherapy during 2-year treatment of drug-naive patients with type 2 diabetes: comparison with metformin. Hormone and Metabolic Research 2008; 40:892-895 